\title{
Physiotherapy and Rehabilitation Implementation in Intensive Care Units: A Survey Study
}

Mousumi Saha' (D), Subhasish Chatterjee ${ }^{2}$ (D)

${ }^{1}$ Department of Cardiothoracic Disorder Physiotherapy, Maharishi Markandeshwar Institute of Physiotherapy and Rehabilitation, Maharishi Markandeshwar (Deemed to be) University, Mullana, Haryana, India

${ }^{2}$ Department of Neurological Physiotherapy, Maharishi Markandeshwar Institute of Physiotherapy and Rehabilitation, Maharishi Markandeshwar (Deemed to be) University, Mullana, Haryana, India

Cite this article as: Saha M, Chatterjee S. Physiotherapy and Rehabilitation Implementation in Intensive Care Units: A Survey Study. Turk Thorac J 2020; 21(2): 138-9.

\section{Dear Editor}

Turkish Thoracic Journal published an interesting and much-needed research article in 2019 by Cakmak et al. [1] titled "Physiotherapy and Rehabilitation Implementation in Intensive Care Units: A Survey Study." We have read the article and found it to be interesting and insightful. This article is informative and assists physiotherapists working in the ICU to implement chest physiotherapy effectively. We noticed some overlooked portions in this research article, which may be considered for further clarifications from the author.

First, the keyword "Intensive Care Unit" used in the abstract of the paper is repeated from the title, which can be replaced with ICU or Critical Care to avoid unnecessary wordiness. More unique keywords can be included, such as Chest Physiotherapy, Respiratory therapy, and Critical Care Physiotherapy, among others.

Second, the researcher mentioned an electronic survey, but did not specifically mention the mode of electronic communication (via emails or any social media). We are unable to determine how the questions are being formed and whether they have used any Google form or survey software.

Third, there is no information on validity of the survey questionnaire used in this study. Since the questionnaire was formed by the authors, it is important to ensure content and face validation before using it in the survey.

Furthermore, with regard to the statistical analysis, the authors have considered the probability value as $<0.05$; however, they have not mentioned the name of the statistical tool used in the study. One of the headings in Table 1 is mean \pm SD, but includes data in the form of counts and percentage. It's better to present two tables. Inter-rater reliability between two independent assessors was mentioned; however, the authors have not named the statistical tool they used to check the same. We implore the authors to mention regarding the internal consistency of the same, which is imperative in reliability testing.

The researchers have well reported the findings of the study, but highlighting the aforementioned issues will make it more acceptable and stronger.

\section{REFERENCE}

1. Çakmak A, İnal İnce D, Sağlam M, et al. Physiotherapy and Rehabilitation Implementation in Intensive Care Units: A Survey Study. Turk Thorac J 2019;20:114-9. [CrossRef]

Address for Correspondence: Subhasish Chatterjee, Department of Neurological Physiotherapy, Maharishi Markandeshwar Institute of Physiotherapy and Rehabilitation, Maharishi Markandeshwar (Deemed to be) University, Mullana, Haryana, India E-mail: subhasishphysio@gmail.com 


\section{Author's Reply}

\section{Re: Physiotherapy and Rehabilitation Implementation in Intensive Care Units: A Survey Study}

Aslıhan Cakmak ${ }^{1}$ (D) Deniz Inal İnce ${ }^{1}$ (D), Melda Sağlam ${ }^{1}$ (D) Sema Savcı ${ }^{2}$ D, Naciye Vardar Yağlı ${ }^{1}$ (D),

Ebru Çalık Kütükcü ${ }^{1}$ (D), Cemile Bozdemir Özel ${ }^{1}$ (D), Hazal Sonbahar Ulu' (D), Hülya Arıkan ${ }^{1}$ (D)

'Department of Physiotherapy and Rehabilitation, Hacettepe University, Faculty of Health Sciences, Ankara, Turkey

${ }^{2}$ Dokuz Eylül University, School of Physical Therapy and

Rehabilitation, İzmir, Turkey

Dear Editor,

We thank Mousumi Saha and Subhasish Chatterjee for their insightful comments and constructive suggestions.

The study aimed to determine the characteristics of physiotherapy practice and critical barriers toward applying physiotherapy in intensive care units. Since the purpose was collecting information about the applications of physiotherapy, while considering the perspective of the physiotherapists working in intensive care units, "intensive care units" was an appropriate word to be used as a keyword. Since the study has been already published, and critical care and intensive care could be used interchangeably, we were unable to change the keyword at this point.

As stated in the methods section, the survey was e-mailed to potential participants and physiotherapists, whose e-mail addresses were acquired from the Turkish Physiotherapy Association database.

We used this survey to collect information about the practice. However, it has not been psychometrically validated since it was not a scale or questionnaire. It is a common approach to collect information if a face-to-face semi-structured interview is not possible or preferred due to geographical difficulties.

As mentioned in Statistical Analysis of the manuscript descriptive statistics, we calculated the mean $\pm S D$, frequencies, and percentages. The open-ended questions were analyzed by two independent assessors who analyzed the responses for the content analysis, the results were clustered and the themes were produced. The inter-rater reliability of the coders was 0.90 .

Sincerely,

Address for correspondence: Aslıhan Çakmak, Department of Physiotherapy and Rehabilitation, Hacettepe University, Faculty of Health Sciences, Ankara, Turkey

E-mail: aslihancakmak90@gmail.com, aslihancakmak@hacettepe.edu.tr

Received: 19.06 .2019

Accepted: 27.06 .2019

Cite this article as: Çakmak A, İnal İnce D, Sağlam M, et al. Re: Physiotherapy and Rehabilitation Implementation in Intensive Care Units: A Survey Study. Turk Thorac J 2020; 21(2): X.

DOI: 10.5152/TurkThoracJ.2019.191431 